\title{
Environmental effects of driving style: impact on fuel consumption
}

\author{
Jakub Lasocki ${ }^{1, *}$, and Karol Boguszewski ${ }^{1}$ \\ ${ }^{1}$ Warsaw University of Technology, Faculty of Automotive and Construction Machinery Engineering, \\ ul. Narbutta 84, 02-524 Warsaw, Poland
}

\begin{abstract}
From an environmental point of view, the fuel consumption of vehicles with combustion engines is directly related to the depletion of non-renewable crude oil resources and pollutant emission. The aim of this paper is to evaluate the effect of driving style on fuel consumption of lightduty vehicles. The study considered five metrics used for quantitative description of driving style: Dynamic Performance Index (DPI), Aggressiveness Factor (AF), Vehicle Aggressivity (VA), Total Aggressivity (TA), based upon the previous works of other researchers, and a newly proposed metric named Driving Style Indicator (DSI). All metrics were applied to the results of chassis dynamometer tests of two light-duty vehicles with spark-ignition and compression-ignition combustion engines. The values of metrics were plotted against corresponding values of fuel consumption to create dependences. Their analysis revealed that AF metric has strong correlation with fuel consumption, but is mathematically complex and requires numerous input data. DSI metric has simple mathematical form and is based only on the speed profile of the vehicle, and yet is characterized by a strong correlation with fuel consumption. DSI metric was further employed to investigate the influence of driving style on greenhouse gas (GHG) emissions from the Well-to-Wheel (WtW) perspective.
\end{abstract}

\section{Introduction}

Fuel consumption is one of the most important features of modern vehicles. First of all, it is clear that a decrease in fuel consumption is beneficial for the environment. The less fuel is used by the internal combustion engine (the more efficient it is), the less exhaust gases are produced, and the less is the consumption of crude oil - a non-renewable resource [1]. In some areas of the world, fuel consumption of vehicles is limited by law (directly or indirectly - in the form of a carbon dioxide emission limit) [2]. Besides, from the consumer's point of view, fuel consumption is directly related to the costs of vehicle use borne by the driver, which is often a decisive factor considered when buying a vehicle. For these reasons, a lot of effort is put into investigating the determinants of the fuel use of vehicles, both at the academic level and in the R\&D centres of the automotive industry [2-7].

Detailed literature review reveals that although there are many factors affecting fuel consumption of vehicles, the most important include: the use of air conditioning devices,

\footnotetext{
${ }^{*}$ Corresponding author: jakub.lasocki@pw.edu.pl
} 
ambient temperature and environmental conditions, roof add-ons, driving style, tyre pressure and vehicle weight $[1,8,9]$. This study focuses on a driving style, which is usually characterised by vehicle speed profile and choice of gears [4, 8]. Aggressive driving is known to increase fuel consumption by up to $24 \%$ [1,2], while eco-driving can lead to certain gains of around $4-10 \%[3,10,11]$ (with some sources claiming even $30 \%$ [1]), compared to standard driving. Therefore driving style optimization is a relatively low-cost and immediate measure to reduce fuel consumption significantly [12]. At the same time it is very difficult to evaluate a personal driving style, as it is one of the most unstable and psychological-related factor [13, 14]. The complexity of driver's behaviour and its connection with vehicle operating parameters is a timely research problem being approached by more and more scientists working in the field of road transport.

One of the main descriptors of personal driving style is the choice of vehicle speed, which has direct implication on fuel consumption [15]. Not only the average value of speed, but also the way the speed changes is of a great importance [16]. For example, intensive acceleration and braking, causing higher fuel consumption $[17,18]$, are often regarded as indicators of driving aggressiveness. Therefore thorough investigation of speed data obtained from real road measurements is the basic approach in the development of driving cycles for testing of pollutant emission and fuel consumption of vehicles in laboratory conditions.

The aim of this paper is to quantify the impact of driving style on fuel consumption of light-duty vehicles and to assess the related environmental effects. Assuming the course of vehicle speed as a representative characteristic of a driving style, different metrics were determined based on the results of chassis dynamometer tests of two vehicles with different type of combustion engine, i.e. spark-ignition (SI) and compression-ignition (CI). Calculated metrics were matched with corresponding values of fuel consumption to create dependencies. Evaluation of those dependencies allowed to choose metric with the best correlation to fuel consumption. This metric was selected to examine the influence of driving style on greenhouse gas (GHG) emission from the Well-to-Wheel (WtW) perspective, which includes not only fuel combustion in the engine, but also the entire chain of fuel production.

\section{Driving style metrics}

A wide range of researchers have studied how fuel consumption is affected by the way a vehicle is driven. Some of these studies made an attempt at defining a metric to be used in the quantitative assessment of this relation. Five such metrics, selected after extensive research, have been considered in the current study.

The first study [19, 20], by Casanova, Fonseca and Espinosa, concerned the link between parameters of driving pattern determined based on signals recorded in a vehicle and pollutant emissions produced over a certain urban route. The Dynamic Performance Index (DPI) has been established in order to classify driving into one of three categories: aggressive, normal or calm. DPI has two different formulas, depending on the type of vehicle's engine. For SI engines the formula is [19]:

$$
D P I_{\mathrm{SI}}=-0.17+0.55 a_{\mathrm{AV}}+0.006 t_{\mathrm{n}>2000}
$$

while for CI engines [20]:

$$
D P I_{\mathrm{CI}}=-0.00158 t_{\mathrm{g} 1}+0.00205 t_{\mathrm{g} 2}+0.0582 a_{\mathrm{AV}}+0.00148 t_{\mathrm{n}>1850}
$$

where: $a_{\mathrm{AV}}$ - average acceleration, $t_{\mathrm{n}>2000} / t_{\mathrm{n}>1850}$ - time share of driving with engine speed higher than $2000 \mathrm{rpm} / 1850 \mathrm{rpm}, t_{\mathrm{g} 1} / t_{\mathrm{g} 2}$ - time share of driving spent in the first/second gear. 
In the next study considered [21] Berry proposed to evaluate driving style using Aggressiveness Factor (AF) that incorporates coast down coefficients used to model resistance which acts on the vehicle in operation, e.g. tire rolling resistance and aerodynamic drag. To achieve the best correlation between aggressiveness factors and fuel consumption, $\mathrm{AF}$ is normalised to vehicle mass and customised to suit different traffic conditions defined by the average vehicle speed. The resulting formulas were named: 'neighbourhood driving' for speed below $32 \mathrm{~km} / \mathrm{h}$, 'city driving' for speed between 32 and $72 \mathrm{~km} / \mathrm{h}$ and 'highway driving' for speed above $72 \mathrm{~km} / \mathrm{h}$. They all have a similar mathematical form, differing only in details. For example, aggressiveness factor used for city driving is given by equation:

$$
A F_{\mathrm{C}}=\frac{1}{\mathrm{M}}\left[\frac{\int\left(\mathrm{A} v+\mathrm{B} v^{2}+\mathrm{C} v^{3}+\mathrm{M} a v\right)^{+} \mathrm{d} t}{\int v \mathrm{~d} t}-F_{\mathrm{r}}\left(v_{\mathrm{AV}}\right)\right]
$$

where: $\mathrm{M}$ - vehicle mass, A, B, C - coast down coefficients, $v$ - speed, $v_{\mathrm{Av}}$ - average speed, $F_{\mathrm{r}}(v)=\mathrm{A}+\mathrm{B} v+\mathrm{C} v^{2}-$ the force of resistance, $a-$ acceleration, $t-$ time.

The third metric considered in this paper is Vehicle Aggressivity (VA) taken from the study by Ford Scientific Research Laboratory [22]. It was found to have a very good correlation with pollutant emission, however did not show as significant match with fuel economy as would be preferred. The advantage of this metric is its simple mathematical form and a limited need for input data:

$$
V A=\sqrt{\frac{1}{N} \sum_{1}^{N}\left(2 v_{\mathrm{i}} a_{\mathrm{i}}\right)^{2}}
$$

where: $N$ - the number of events that occur in a drive cycle, $v$-speed, $a$-acceleration.

Ford's original concept of VA was further extended by MAHLE Powertrain Ltd. Pedal Aggressivity (PA), a factor related to the position of the accelerator pedal, was added [23]:

$$
P A=\sqrt{\frac{1}{N} \sum_{1}^{N}\left(2 s_{\mathrm{i}} s_{\mathrm{i}}^{\prime}\right)^{2}}
$$

where: $s$ - relative position of the accelerator pedal for given acceleration profile, $s$ ' - the average rate of the relative position of the accelerator pedal for this profile.

In contrast to Ford's metrics, MAHLE's VA considers only positive vehicle acceleration. Another unique feature of this method is averaging speed and acceleration over an acceleration profile (that goes between adjacent minimum and maximum) and then their normalization by the number of events (acceleration profiles considered). This same technique is used for the PA as well. VA is combined with PA into one metric called Total Aggressivity (TA):

$$
T A=\sqrt{V A}+\sqrt[4]{P A}
$$

The goal of TA metric is to alleviate the differences between vehicles, which characteristics (e.g. power output) affect the driving dynamics, and thus to focus primarily on the impact of the driver. In other words, TA helps normalize between vehicles.

In search of a simplified way of assessing the impact of driver's driving style on fuel consumption, a new metric has been developed in this study. The starting point was driving aggressivity metric proposed by Stichter [24], which combines average positive and negative vehicle acceleration with vehicle speed - three parameters that are known to correlate well with fuel consumption. The original idea of Stichter has been implemented in current research 
with an emphasis on obtaining a maximally simplified mathematical form. In this way, the Driving Style Indicator (DSI) was proposed as follows:

$$
D S I=\frac{a_{\mathrm{AV}}^{+}-a_{\mathrm{AV}}^{-}}{v_{\mathrm{AV}}}
$$

where: $a^{+} \mathrm{AV}-$ average positive acceleration of a vehicle, $a_{\mathrm{AV}}^{-}$- average negative acceleration (deceleration) of a vehicle.

Each metric outlined in this section was used for the investigation of the effect of driving style on fuel consumption of light-duty vehicles.

\section{Materials and methods}

The general concept of the study was to determine the dependences of fuel consumption on the driving style metrics using results of testing vehicles in standard driving cycles, on a chassis dynamometer. It is therefore assumed that the driver's driving style is expressed exclusively by the speed of a vehicle, or specifically by the speed profile imposed by a given driving cycle. In the next step, the environmental impact of driving style was quantified by linking the dependencies obtained to total GHG emission, in line with the WtW approach.

The study was conducted based on previously published data gathered at the Advanced Powertrain Research Facility of Argonne National Laboratory in the USA [25]. The tests were carried out using a chassis dynamometer with rollers of $1.22 \mathrm{~m}$ diameter, able to provide variable equivalent inertia weight of $136-5443 \mathrm{~kg}$. Test cell conditions, i.e. temperature, humidity, and solar load, were fully controlled. Detailed specifications of testing equipment can be found in [25].

The testing included two vehicles: Dodge RAM with SI combustion engine (hereinafter referred to as vehicle 1) and Chevrolet Cruise with CI combustion engine (hereinafter referred to as vehicle 2). Their main technical specifications are shown in Table 1.

Table 1. Specifications of the tested vehicles.

\begin{tabular}{|c|c|c|c|}
\hline Parameter & Unit & Vehicle 1 & Vehicle 2 \\
\hline Make and model & & Dodge RAM & Chevrolet Cruise \\
\hline Model year & & 2013 & 2014 \\
\hline Curb/test mass & $\mathrm{kg}$ & $2074 / 2245$ & $1587 / 1727$ \\
\hline Engine type & & $\mathrm{SI}$ & $\mathrm{CI}$, turbocharged \\
\hline Engine displacement & $\mathrm{cm}^{3}$ & 3604 & 1956 \\
\hline Maximum power (at engine speed) & $\mathrm{kW}(\mathrm{rpm})$ & $227(6400)$ & $112(4000)$ \\
\hline Maximum torque (at engine speed) & $\mathrm{N} \cdot \mathrm{m}$ & $365(4175)$ & $358(2600)$ \\
\hline Transmission type & & 8 -speed automatic & \begin{tabular}{c} 
6-speed automatic \\
\hline Other features
\end{tabular} \\
\hline
\end{tabular}

Seven different driving cycles were performed on a chassis dynamometer, including FTP-72, HWFET, US06, WLTC, NEDC, NYCC and LA92. Vehicle 1 was subjected to all of them, while in the case of vehicle 2 the last two cycles were omitted. In order to achieve bigger accuracy of dependencies determined, WLTC and NEDC cycles were split into phases of which they are composed. The values of driving style metrics described in section 2 of this paper were calculated for the actual speed course of the vehicle, which is always slightly different from the nominal one defined by the driving cycle. 
The DPI $\mathrm{CI}_{\mathrm{CI}}$ metric, intended to be used for vehicles with CI engines, was not applied for vehicle 2 due to the lack of data on the time share of driving in individual gears. AF metric was calculated separately for the three ranges of vehicle average speed, according to the original concept of Berry, although this does not agree with the formal classification of some driving cycles (e.g. the EUDC simulating 'extra-urban' conditions was classified as city driving). TA metric was considered only for vehicle 1, due to the lack of data on the position of the accelerator pedal for vehicle 2 . Besides, this metric was slightly modified in accordance with the Stichter proposal [24], i.e. instead of looking at an acceleration profile, speed points for each individual time interval were considered.

In order to evaluate the relationship of driving style with the environmental effects of vehicle use, data from the WtW analysis were employed. This approach allows to quantify environmental load of the production, transport and distribution of fuels (Well-to-Tank, $\mathrm{WtT}$ ), as well as of fuel combustion in the vehicle's engine (Tank-to-Wheel, TtW). The methodology considered in this paper is presented in detail in the report of JRC-EucarConcawe consortium (JEC) [26]. The most important assumptions for the calculations made in the current study include:

- WtT GHG emission factors: gasoline - $13.8 \mathrm{~g}_{\mathrm{CO} 2 \mathrm{eq}} / \mathrm{MJ}$, diesel oil - $15.4 \mathrm{~g}_{\mathrm{CO} 2 \mathrm{eq}} / \mathrm{MJ}$ [26],

- TtW GHG emission factors: gasoline - $73.4 \mathrm{~g}_{\mathrm{CO} 2 \mathrm{eq}} / \mathrm{MJ}$, diesel oil - $73.2 \mathrm{~g}_{\mathrm{CO} 2 \mathrm{eq}} / \mathrm{MJ}$ [26],

- global warming potentials (in time horizon of 100 years): $\mathrm{CO}_{2}-1, \mathrm{CH}_{4}-23, \mathrm{~N}_{2} \mathrm{O}-296$,

- heating value of fuels used in tests: gasoline $-42.64 \mathrm{MJ} / \mathrm{kg}$, diesel oil - $42.80 \mathrm{MJ} / \mathrm{kg}$ [25],

- density of fuels used in tests: gasoline $-0.741 \mathrm{~kg} / \mathrm{dm}^{3}$, diesel oil $-0.851 \mathrm{~kg} / \mathrm{dm}^{3}$ [25].

\section{Results and discussion}

Fuel consumption of vehicles, related to the distance travelled, was plotted against the values of driving style metrics. The resulting dependences are presented in Figures 1-5.

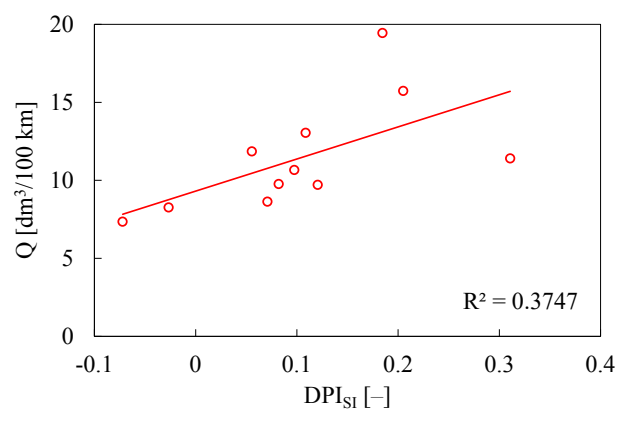

Fig. 1. The dependence of fuel consumption on DPsi for vehicle 1 .
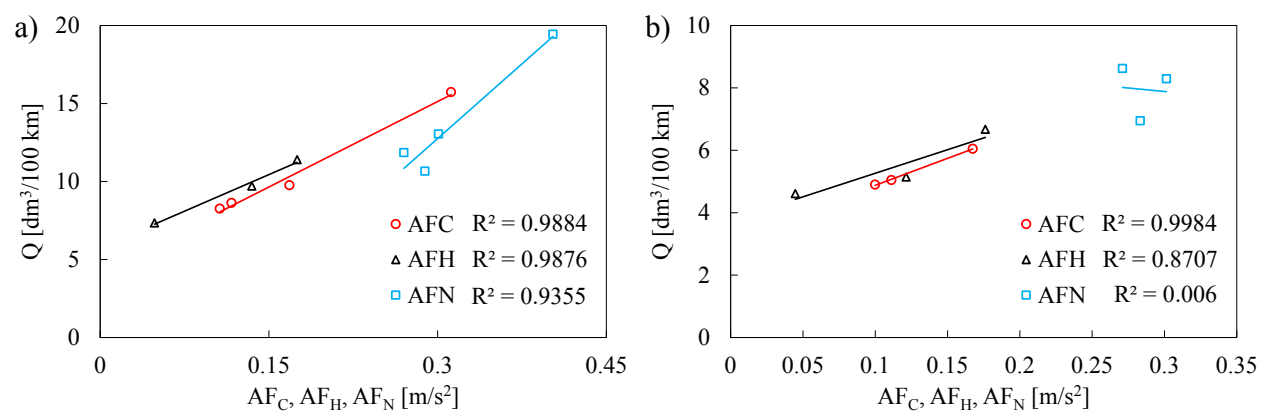

Fig. 2. The dependence of fuel consumption on AF for: a) vehicle 1, b) vehicle 2. 

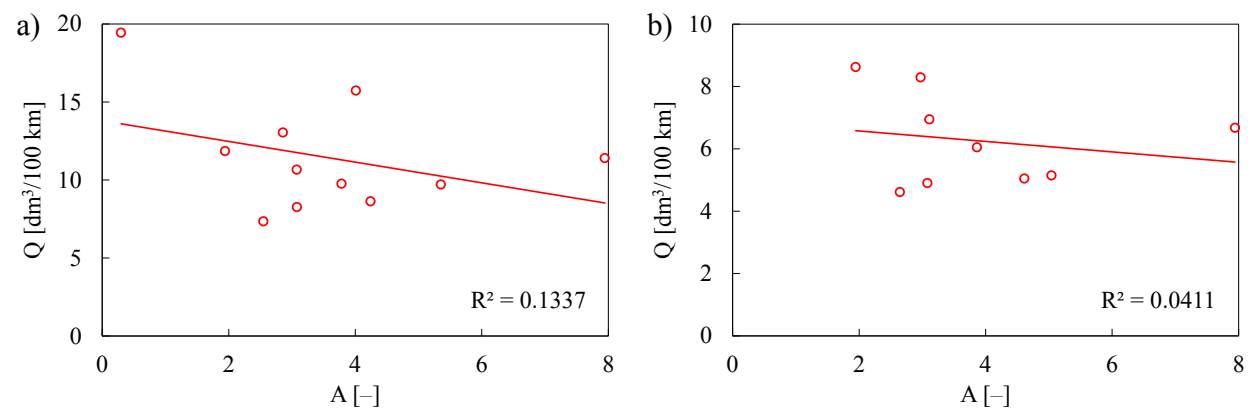

Fig. 3. The dependence of fuel consumption on A for: a) vehicle 1, b) vehicle 2 .

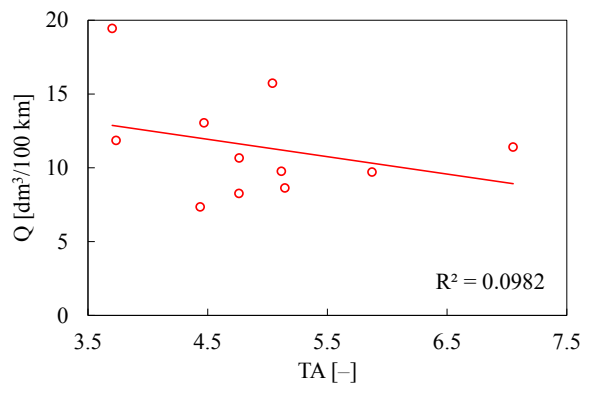

Fig. 4. The dependence of fuel consumption on TA for vehicle 1.
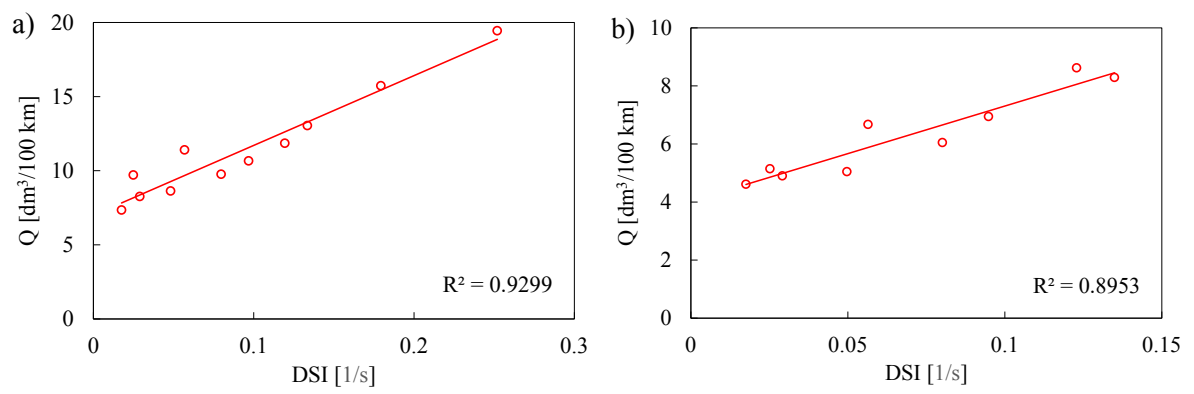

Fig. 5. The dependence of fuel consumption on DSI for: a) vehicle 1, b) vehicle 2 .

Analysing the obtained results, it can be seen that metrics A and TA have definitely the worst correlation with fuel consumption. The $\mathrm{R}^{2}$ values of the linear trend line drawn are around 0.1 or lower for both vehicles. It should be noted, however, that metrics A and TA were intended by their authors to assess pollutant emissions and not fuel consumption. $\mathrm{DP}_{\mathrm{SI}}$ metric is somewhat better correlated with fuel consumption, but still it is not a sufficient dependence, because the $\mathrm{R}^{2}$ value is only about 0.37 . In contrast, AF was found to have very strong correlation to fuel consumption, having $\mathrm{R}^{2}$ values that exceed 0.9 . Being specific, the best results were obtained for urban driving conditions to which the $\mathrm{AF}_{\mathrm{C}}$ metric is applied. This is true for both vehicles. Similarly, for high speed driving, fuel consumption is strongly correlated with $\mathrm{AF}_{\mathrm{H}}$ metric. In the case of low-speed driving $\left(\mathrm{AF}_{\mathrm{N}}\right)$, called 'neighbourhood driving' by Berry, this relationship is rather ambiguous. On the one hand, a strong dependence was obtained for vehicle 1 , with $\mathrm{R}^{2}$ at the level of 0.94 , while on the other hand a very weak dependence, with $\mathrm{R}^{2}$ being much less than 0.01 was achieved for vehicle 2 . Despite this, the AF is actually the only driving style metric derived from other authors' research that showed close dependency with fuel consumption. The new metric - DSI, 
proposed in this study, allows to obtain comparatively good results. This is confirmed by the $\mathrm{R}^{2}$ values of the linear trend lines, which are 0.93 and 0.90 for vehicle 1 and vehicle 2 , respectively. It must be emphasized that these results were obtained using data from all driving cycles, regardless of the vehicle's average speed. It shows the universality of the new metric. Another advantage of DSI over AF is a small number of input data necessary for calculations and no need to determine the vehicle's coast down coefficients. DSI metric has been selected for further research into the impact of driving style on GHG emission. The reasons behind this choice were twofold: strong correlation with fuel consumption and its almost linear character. Figure 6 shows the resultant dependence of GHG emission on DSI metric, obtained for both vehicles.

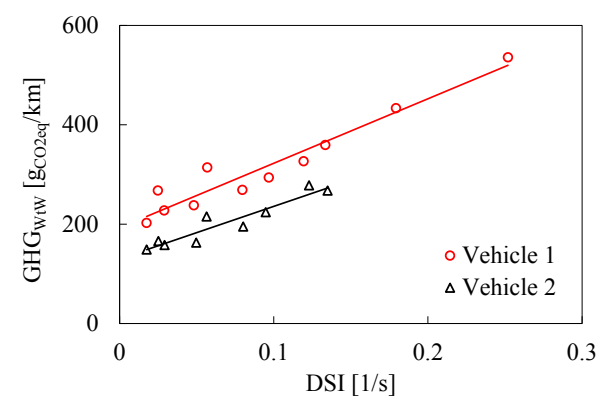

Fig. 6. The dependence of Well-to-Wheel GHG emission on DSI for vehicles 1 and 2.

For obvious reasons, the dependencies determined in this way are strongly related to the properties of the vehicle and fuel, but for a specific case, this approach can be recommended for predicting the approximate effects of driving style in terms of GHG emission. When assessing the results presented, the limitations of this study should be kept in mind. First of all, a relatively small number of driving cycles has been included. This is especially evident in the case of AF metric, where sometimes three points had to suffice to infer dependence on fuel consumption. Secondly, the driving cycles performed on a chassis dynamometer do not fully reflect the actual driving conditions of vehicles in road traffic. It would therefore be beneficial to carry out further studies in road traffic. This can be a future direction of development of this work.

\section{Conclusions}

Based on the research described in this paper, the following conclusions can be drawn:

- To evaluate the impact of a driving style on fuel consumption, certain metrics can be used, which combine parameters characterizing the course of vehicle speed, gear changes, engine speed and technical specifications of the vehicle.

- The dependence of fuel consumption on driving style metrics known from the literature is approximately linear.

- Driving style metrics known from the literature can be divided into two groups: those strongly correlating with fuel consumption, but requiring numerous input data, sometimes difficult to access, and those to which data is readily available, but giving results with a relatively weaker correlation.

- The new metric, Diving Style Indicator (DSI), proposed in this study is not mathematically complicated and is based only on the data regarding the speed of the vehicle, and yet is characterized by a strong correlation with fuel consumption.

- It is possible to employ selected metrics for predicting the approximate environmental effects of driving style in terms of GHG emission associated with the use of fuel. 


\section{References}

1. N. Zacharof, G. Fontaras, B. Ciuffo, S. Tsiakmakis, K. Anagnostopoulos, A. Marotta, J. Pavlovic, Review of in use factors affecting the fuel consumption and $\mathrm{CO}_{2}$ emissions of passenger cars (Publications Office of the European Union, Luxembourg, 2016)

2. L. Schipper, Transport Policy 18, 358-372 (2011)

3. B. Beusen, S. Broekx, T. Denys, C. Beckx, B. Degraeuwe, M. Gijsbers, K. Scheepers, L. Govaerts, R. Torfs, L.I. Panis, Transport. Res. D-Tr. E. 14, 514-520 (2009)

4. K. Brundell-Freij, E. Ericsson, Transport. Res. D-Tr. E. 10, 213-229 (2005)

5. A. Kopczyński, Z. Liu, P. Krawczyk, E3S Web of Conferences 44, 00074 (2018)

6. W. Gis, J. Pielecha, J. Waśkiewicz, M. Gis, M. Menes. IOP Conf. Ser.-Mat. Sci. 148 (2016)

7. A. Kopczyński, P. Piórkowski, P. Roszczyk, IOP Conf. Ser.-Mat. Sci. 421, 022016 (2018)

8. E. Ericsson, Transport. Res. D-Tr. E. 5, 213-229 (2005)

9. A. Kopczyński, P. Krawczyk, J. Lasocki, E3S Web of Conferences 44, 00073 (2018)

10. J. N. Barkenbus, Energ. Policy 38, 762-769 (2010)

11. I. Jeffreys, G. Graves, M. Roth, Transport. Res. D-Tr. E. 60, 85-91 (2018)

12. Y. Huang, E. C. Y. Ng, J. L. Zhou, N. C. Surawski, E. F. C. Chan, G. Hong, Renew. Sust. Energ. Rev. 93, 596-609 (2018)

13. Y. Lei, K. Liu, Y. Fu, X Li, Z. Liu, S. Sun, Research on driving style recognition method based on driver's dynamic demand, Adv. Mech. Eng. 8, 1-14 (2016)

14. Y. Wang, W. Qu, Y. Ge, X. Sun, K. Zhang, Plos One 13, e0202126 (2018)

15. Z. Chłopek, J. Lasocki, P. Wójcik, A. J. Badyda, Int. J. Green Energy 15, 773-779 (2018)

16. Z. Chłopek, J. Biedrzycki, J. Lasocki, P. Wójcik, Eksploatacja i Niezawodnosc Maintenance and Reliability 17, 35-41 (2015)

17. A. Szumanowski, Y. Chang, Z. Liu, P. Krawczyk, Int. J. Vehicle Des. 76, 1-19 (2018)

18. J. Merkisz, M. Gis. E3S Web of Conferences 44, 00109 (2018)

19. J. Casanova, N. Fonseca, F. Espinosa, Proc. $17^{\text {th }}$ Transport and Air Pollution Symp. and $3^{\text {rd }}$ Environment and Transport Symp., 2-4 June 2009, Toulouse, France (2009)

20. N. Fonseca, J. Casanova, F. Espinosa, Proc. $18^{\text {th }}$ International Symp. Transport and Air Pollution, 18-19 May 2010, Dübendorf, Switzerland (2010)

21. I. Berry, The effects of driving style and vehicle performance on the real-world fuel consumption of U.S. light-duty vehicles $(\mathrm{PhD}$ thesis, Massachusetts Institute of Technology, Massachusetts, 2010)

22. E. K. Nam, C. A. Gierczak, J. W. Butler, A comparison of real-world and modeled emissions under conditions of variable driver aggressiveness $\left(82^{\text {nd }}\right.$ Annual Meeting of the Transportation Research Board, 12-16 January 2003, Washington DC, 2003)

23. R. Daniel, T. Brooks, D. Pates, SAE Technical Paper, 2009-01-0236 (2009)

24. J. S. Stichter, Investigation of vehicle and driver aggressivity and relation to fuel economy testing ( $\mathrm{PhD}$ thesis, University of Iowa, Iowa, 2012)

25. Argonne National Laboratory, https://www.anl.gov/ [online] [accessed 24.01.2019]

26. JEC (JRC-Eucar-Concawe), Well-To-Wheels Report Version 4.a: Well-to Wheels Analysis of Future Automotive Fuels and Powertrains in the European Context (Publications Office of the European Union, Luxembourg, 2014) 